\title{
Alternative Biodefensive based on the Essential Oil from Allium sativum Encapsulated in PCL/Gelatin Nanoparticles
}

\author{
Larissa Medeiros de Oliveira ${ }^{1}$, Laiane S. Silva ${ }^{1}$, Josiana M. Mar ${ }^{1,2}$, Sidney G. Azevedo ${ }^{1,2}$, \\ Maxwaldo S. Rabelo ${ }^{1}$, Henrique D. da Fonseca Filho ${ }^{3}$, Suzan Xavier Lima ${ }^{1}$, Jaqueline de A. \\ Bezerra $^{2,4}$, Marcos B. Machado ${ }^{2}$, Pedro H. Campelo ${ }^{1,5}$, Edgar A. Sanches ${ }^{1}$ \\ 1. Laboratório de Polímeros Nanoestruturados (NANOPOL), Universidade Federal do Amazonas (UFAM), \\ Manaus/AM, Brasil \\ 2. Núcleo de Estudos Químicos de Micromoléculas da Amazônia (NEQUIMA), Universidade Federal do \\ Amazonas (UFAM), Manaus/AM, Brasil \\ 3. Departamento de Física, Universidade Federal do Amazonas (UFAM), Manaus/AM, Brasil \\ 4. Instituto Federal de Educação Ciência e Tecnologia do Amazonas (IFAM), Manaus/AM, Brasil \\ 5. Faculdade de Ciências Agrárias, UFAM, Manaus/AM, Brasil
}

Received: 22 May 2019; Accepted: 24 June 2019; Available online: 31 August 2019

\begin{abstract}
The goal of this paper was to develop a biodegradable system containing the essential oil from Allium sativum bulbs encapsulated in PCL/gelatin-based nanoparticles, as well as evaluate its efficiency to control Aedes aegypti Linn. larvae and Cerataphis lataniae Bois. aphids. The essential oil was analyzed by GC-FID and GC-MS, and six compounds were identified, representing $93.1 \%$ of the total oil. The major compounds were diallyl trisulfide (51.8\%), diallyl disulfide (23.2\%) and allyl methyl trisulfide (13.6\%). The PCL/gelatin-based nanoparticles containing this essential oil exhibited encapsulation efficiency higher than 94\%, average particle diameter around $200 \mathrm{~nm}$ and zeta potential values about $-36 \mathrm{mV}$. The essential oil presented no antioxidant nor enzymatic activities, so its effectiveness might be explained by the presence of sulfur compounds. The release kinetics of the encapsulated essential oil confirmed the release mechanism by the Fick's Law. About $50 \%$ of the encapsulated essential oil was released after $1 \mathrm{~h}$, and about $90 \%$ was released after $50 \mathrm{~h}$. This behavior is interesting from the technological point of view since the nanoparticles released as much oil as possible in a short period of time and then the lethal dosages were maintained along the time. Nanoparticles containing the encapsulated essential oil was submitted to in vitro bioassays against $A$. aegypti and C. lataniae and showed $100 \%$ of mortality against larvae and aphids up to $24 \mathrm{~h}$. In conclusion, the essential oil from $A$. sativum presented effectiveness to be applied in sustainable management of pests in greenhouses, as well as for larvicidal control.
\end{abstract}

Keywords: Allium sativum; Bioassay; Encapsulation; Gelatin nanoparticles.

\section{Introduction}

Garlic and the other Allium species have been known since ancient times due to their health benefits [1]. Commonly used for culinary purposes, garlic is also interestingly appreciated due to its therapeutic and medicinal properties, both in traditional and modern medicine and agronomy [2].

The bioactivity effect of the in natura and encapsulated essential oil from Allium sativum bulbs (Asparagale: Amaryllidaceae) was evaluated in this work against larvae (Aedes aegypti Linn.) and aphids (Cerataphis lataniae Boisd.). These common pests in tropical and subtropical countries are currently causing severe damages in human health, as well as in food crops and greenhouses. The mosquito A. aegypti Linn., vector of the yellow and dengue hemorrhagic fever, has been widely distributed in tropical and subtropical zones. Nowadays the main control strategies have been based on the use of synthetic chemical products, which may lead to the development of mosquito resistance and environmental contamination [3]. On the other hand, the palm aphid, Cerataphis lataniae Boisd., is a local pest of açaí palms (Euterpe oleracea Martus and E. precatoria Martus) that may cause death of young plants or early fall of flowers and fruits [4].

The use of nanotechnology-based food chemistry to combat pests represents an interesting area of research [5-

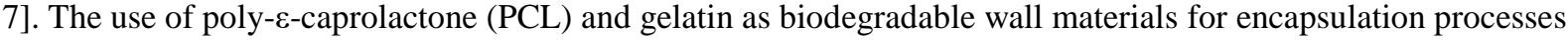
are based on the facts that they are FDA approved, biodegradable, non-toxic, easy to crosslink and to modify chemically and has potential to be used for drug delivery systems [8]. For this reason, PCL and gelatin-based nanoparticles have been used successfully as a carrier for drugs and bioactive molecules [8-11]. However, the 
volatility of essential oils and the sensibility toward oxygen and light reduce its stability in processing and storage. To overcome these drawbacks, researchers have encapsulated essential oils in different types of nanoparticles [12], representing a viable and efficient controlled release approach that increase their physical stability [13].

Controlled release formulations using biopolymeric nanoparticles are of special interest because of the possible biological degradation of the matrices when the duration of action has finished, and also due to the relatively low cost [14]. In this work a viable encapsulation methodology was proposed using PCL/gelatin-based nanoparticles with good size distribution to serve as carriers for the $A$. sativum essential oil. The potential of the encapsulated essential oil was assessed against the A. aegypti Linn. and C. lataniae Boisd. Physicochemical characterization of the encapsulated nanoparticles considered the following parameters: size distribution using Atomic Force Microscopy (AFM) measurements, polydispersity index (PDI), zeta potential and encapsulation efficiency using Fourier-transform Infrared Spectroscopy (FTIR). Keeping in view the nanotechnology-based food chemistry for natural controlling agent's activity, the present work would be useful for the development of a new effective controlling agent based on encapsulated bioactive chemical compounds from the Allium sativum bulbs.

\section{Materials and methods}

\subsection{Essential oil characterization}

Allium sativum bulbs were collected in Manaus/AM - Brazil and dried in controlled humidity at $30^{\circ} \mathrm{C}$ until reach constant weight. Then, $400 \mathrm{~g}$ of milled bulbs were subjected to hydrodistillation using a Clevenger-type apparatus for $2 \mathrm{~h}$ at $100^{\circ} \mathrm{C}$. The essential oil was dried over anhydrous sodium sulphate and stored at $-18{ }^{\circ} \mathrm{C}$. Essential oil yield was obtained by the ratio between the extracted oil volume to the plant material mass.

Relative density of the essential oil was estimated at $20^{\circ} \mathrm{C}$. Two washed, dried capillary tubes were taken for this purpose. One of them was filled with distilled water $\left(m_{1}\right)$ and another with essential oil $\left(m_{2}\right)$. Both filled tubes and a similar empty tube were weighed, and the relative density was obtained according to the equation [d $=\left(m_{2}\right.$ $\left.-m_{1}\right) /\left(m_{1}-m\right)$ ], where $m$ is the mass of the empty capillary tube. Finally, the density value was converted by the water table density [15]. The refraction index of the essential oil in natura was estimated at $20^{\circ} \mathrm{C}$ using an $\mathrm{ABBE}$ refractometer model DR-A1.

GC-MS analysis was carried out using a Trace GC Ultra coupled ISQ Single Quadrupole MS instrument (Thermo Scientific). The operating conditions were as follows: TR-5 ( $0.25 \mathrm{~mm}$ x $30 \mathrm{~m}, 0.25 \mu \mathrm{m}$ coating thickness) fused silica capillary column, injector and detector temperatures were $250^{\circ} \mathrm{C}$; helium was used as carrier gas at a flow rate of $1.0 \mathrm{~mL}$. $\mathrm{min}^{-1}$; column was heated from $40^{\circ} \mathrm{C}$ to $240^{\circ} \mathrm{C}$ with a rate of $4{ }^{\circ} \mathrm{C}$. $\mathrm{min}^{-1}$. The split ratio was 1:40. The MS profile was obtained at $70 \mathrm{eV}$ with acquisition mass range of $40-400 \mathrm{Da}$.

Identification of the isolated compounds was established from their GC retention index using a $n$-alkanes homologous series whose Arithmetic Index (AI) were calculated using the van der Dool-Kratz equation [16]. Moreover, the identifications of the essential oil compounds were also confirmed using published data as well as through the Nist of Mass Spectral Data [17], and Pherobase [18].

\subsection{Antioxidant (DPPH', ABTS ${ }^{*+}$ ) and acetylcholinesterase (AChE) inhibitory activities}

The radical scavenging ability of the essential oil was evaluated using the $\mathrm{DPPH}^{\cdot}$ radical [19] with slight modifications. An aliquot of $\mathrm{DPPH}^{*}$ methanolic solution was prepared. Then, $20 \mu \mathrm{L}$ of essential oil in five concentrations obtained by series dilution (31.2 to $1.9 \mu \mathrm{g} \cdot \mathrm{mL}^{-1}$ ) was added to $180 \mu \mathrm{L}$ of DPPH' methanolic solution. Quercetin was used as positive control (25.0 to $\left.1.6 \mu \mathrm{g} . \mathrm{mL}^{-1}\right)$. The mixture was kept in the dark at room temperature for $0.5 \mathrm{~h}$. The absorbance was measured at $515 \mathrm{~nm}$. The inhibition percentage was obtained according to the equation: [100 - (absorbance/average absorbance of control) x 100]. The IC $_{50}$ was defined as the amount of essential oil needed to inhibit the $\mathrm{DPPH}^{*}$ radical formation by $50 \%$. The assay was carried out in triplicate.

The radical scavenging capacity of the essential oil was evaluated using the ABTS method [20] with some modifications. The ABTS radical cation $\left(\mathrm{ABTS}^{*+}\right)$ solution was prepared using ABTS (7 mM) and $\mathrm{K}_{2} \mathrm{~S}_{2} \mathrm{O}_{8}(140$ $\mathrm{mM}$ ) at room temperature. The absorbance of the resulting $\mathrm{ABTS}^{{ }^{++}}$solution was adjusted for $0.70 \pm 0.05$ at 750 nm using ethanol. Then, $3 \mu \mathrm{L}$ of the resulting sample at different concentrations (from 62.5 to $1.9 \mu$ g.mL ${ }^{-1}$ ) was diluted in $300 \mu \mathrm{L}$ of the $\mathrm{ABTS}^{*+}$ solution. Trolox was used for the calibration curve (100 a $\left.2000 \mu \mathrm{M}\right)$.

AChE inhibitory activity of the essential oil was performed based on the method described previously [21] with some modifications. Solutions prepared with $20 \mu \mathrm{L}$ of sample $\left(500.0-7.8 \mu \mathrm{g} . \mathrm{mL}^{-1}\right)$, $80 \mu \mathrm{L}$ of phosphate buffer (100 mM), $40 \mu \mathrm{L}$ of dithiobisnitrobenzoic acid (DTNB, $2.5 \mathrm{mM})$, and $20 \mu \mathrm{L}$ of AChE (1.0 U.mL ${ }^{-1}$ ) were added to each microplate well at $37^{\circ} \mathrm{C}$ for $10 \mathrm{~min}$. Then, $40 \mu \mathrm{L}$ of acetylcholine iodide (AtCHI, $10 \mathrm{mM}$ ) was added and incubated again in the same conditions. Then, $60 \mu \mathrm{L}$ of sodium dodecylsulphate (SDS, 1\%) was added as reaction terminator. The mixture absorbance was measured at $405 \mathrm{~nm}$. The percentage inhibition of AChE activity was calculated by [Inhibition $(\%)=\left(A_{2}-\left(A_{1}-A_{3}\right) \times 100\right) / A_{2}$, where $A_{1}$ is the sample and enzyme absorbance, $A_{2}$ is the enzyme absorbance, and $A_{3}$ is the tested sample absorbance. The $\mathrm{LD}_{50}$ was obtained by curves of each 
inhibitor toward AChE. The assay was carried out in duplicate. Galantamine was used as standard from 25.0 to $1.6 \mu \mathrm{g} . \mathrm{mL}^{-1}$.

\subsection{Bioassays using the in natura essential oil}

Bioassays were conducted to test the A. sativum essential oil against $A$. aegypti Linn. larvae based on previous work [22] with some modifications. All bioassays were performed at $26 \pm 2{ }^{\circ} \mathrm{C}$ and $90 \% \mathrm{RH}$. Essential oil/dimethyl sulfoxide (DMSO) solutions $(10 \mathrm{~mL})$ were prepared at 500, 250, 100, 50 and $25 \mu \mathrm{g} \cdot \mathrm{mL}^{-1}$. Then, 500 larvae at $3^{\text {rd }}$ instar were divided in 5 groups for each tested concentration. DMSO and temephos were used as negative and positive control, respectively. This bioassay was carried out in quintuplicate. The larvicidal activity was estimated by the larvae mortality after $24 \mathrm{~h}, 48 \mathrm{~h}$ and $72 \mathrm{~h}$ of exposure. Data were analyzed in POLO PC® program [23] for calculations of the $\mathrm{LD}_{50}$ (Lethal Concentration that kills $50 \%$ of the exposed larvae), $\mathrm{LD}_{90}$ (Lethal Concentration that kills $90 \%$ of the exposed larvae), LCL (Lower Confidence Limit) and UCL (Upper Confidence Limit) with fiducial limit of $95 \%$.

Evaluation of the insecticidal potential of the essential oil was based on previous works [24,25]. Glass Petri plates (90 mm × $20 \mathrm{~mm}$; $130 \mathrm{~mL}$ air space) were used as a chamber for the evaluation of the essential oil's volatile phase effect. C. lataniae Boisd. population was obtained from stock colonies of açaí palm (Euterpe oleracea Martus) without any pesticide exposure. Dorsal side leaves were placed on filter paper saturated with $1 \%$ sodium hypochlorite. Ten adults were transferred from stock using a soft paintbrush and allowed to settle before exposure. Essential oil solutions were applied on filter paper disks placed at the inner surface of the Petri dish lid. A portion of $10 \mu \mathrm{L}$ of essential oil/dimethyl sulfoxide (DMSO) solution (1.0, 0.50, 0.25, 0.10, 0.062 and 0.031\%) was added on filter paper disk. Plates were sealed to prevent loss of essential oil. These bioassays were carried out in triplicate. DMSO and thymol (3.0 $\left.\mu \mathrm{g} . \mathrm{mL}^{-1}\right)$ were used as negative and positive control, respectively. Mortality was evaluated after $24 \mathrm{~h}, 48 \mathrm{~h}$ and $72 \mathrm{~h}$ of exposition. Aphids were considered dead if they did not move when prodded with a fine paintbrush. The mortality data were subjected to the PROBIT analysis [26] for calculations of the $\mathrm{LD}_{50}, \mathrm{LD}_{90}$, LCL and UCL with fiducial limit of 95\%.

\subsection{Essential oil encapsulation}

Two different solutions were prepared for the synthesis of PCL/gelatin-based nanoparticles. Solution I: Gelatin was heated to $50^{\circ} \mathrm{C}$ in distilled water under constant stirring. Then, tween $80(0.30 \mathrm{~g})$ was solubilized when temperature decreased to $40^{\circ} \mathrm{C}$. Solution II: PCL (0.05 g), Span 60 (0.02 g) and TACC (0.1 g) were solubilized in dichloromethane. Essential oil (350 $\left.\mu \mathrm{g} \cdot \mathrm{mL}^{-1}\right)$ was added to Solution II. After the essential oil solubilization, Solution II was added to the Solution I using an ultra disperser. Transglutaminase was added to the final solution under constant stirring for $15 \mathrm{~min}$.

\subsection{Atomic Force Microscopy (AFM)}

Nanoparticle topography was obtained with an AFM (Innova, Bruker) on an area of $(10 \times 10) \mu m^{2}$, operated in contact mode using silicon nitride cantilevers. Measurements were performed at room temperature $(296 \pm 1 \mathrm{~K})$ and $40 \pm 1 \%$ relative humidity with $512 \times 512$ pixels at a scan rate of $1.0 \mathrm{~Hz}$. The feedback control was adapted to the surface and analyzed using the WSxM software [27]. The topography images were plane fitted and the average height of the image lines were adjusted with a flatten filter of zero order. The nanoparticles were deposited on a glass blade until solvent evaporation. Particle size distribution was performed using the Image J. program [28].

\subsection{Zeta potential}

The zeta potential values (in $\mathrm{mV}$ ) were determined by electrophoresis using a Zetasizer Nano ZS90 instrument (Malvern Instruments, UK). Samples (unloaded and loaded nanoparticles containing $350 \mu \mathrm{g} . \mathrm{mL}^{-1}$ of essential oil) were analyzed in triplicate, at $25^{\circ} \mathrm{C}$.

\subsection{Encapsulation efficiency}

Entrapment efficiency of the essential oil on the developed PCL/gelatin-based nanoparticles was analyzed using UV-Vis spectroscopy based on previous work [8] with some modifications. A known concentration of essential oil in ethanol was scanned in the range of $190-400 \mathrm{~nm}$ using a UV-vis spectrophotometer (Global Trade Technology). A sharp peak was noticed for the A. sativum essential oil. The absorbance values were recorded and plotted. From the calibration curves, the unknown concentration of essential oil was obtained by knowing the absorbance value. Nanoparticles were separated by centrifugation and the supernatant absorbance was used to determine the amount of free essential oil which was not encapsulated. The encapsulation efficiency (EE) was calculated using the formula: \%Encapsulation Efficiency (EE) = (amount of encapsulated essential oil/ total amount of essential oil used in the formulation)*100. 


\subsection{In vitro essential oil release}

In vitro essential oil release studies were carried out in $150 \mathrm{~mL}$ flasks, where $10 \mathrm{~mL}$ of loaded nanoparticles dispersion containing an absolute concentration of $350 \mu \mathrm{g} \cdot \mathrm{mL}^{-1}$ of essential oil was taken in dialysis tubing cellulose membrane and suspended in water $(90 \mathrm{~mL})$ at $25^{\circ} \mathrm{C}$. The nanoparticle dispersion was continuously stirred at $100 \mathrm{rpm}$ using a mechanical stirring. A $2 \mathrm{~mL}$ aliquot was withdrawn at regular time intervals and their absorbance was measured using an UV-vis spectrophotometer. The amount of released essential oil was quantified using the standard curve [10]. The \% cumulative release of essential oil was calculated by using the following equation: [Cumulative release $(\%)=$ (amount of essential oil released after time $t /$ total amount of essential oil encapsulated in nanoparticles)*100]. The experiments were carried out in triplicate.

\subsection{Bioassays using the encapsulated essential oil}

The toxicity of the encapsulated essential oil was tested against A. aegypti Linn larvae. All bioassays were performed at $26 \pm 2{ }^{\circ} \mathrm{C}$ and $90 \%$ RH in a photoperiod regimen of $12: 12 \mathrm{~h}$. Loaded nanoparticles $(10 \mathrm{~mL})$ were prepared at $350 \mu \mathrm{g} \cdot \mathrm{mL}^{-1}$. Then, 200 larvae at $3^{\text {rd }}$ instar were divided in 10 groups for each tested concentration. Unloaded nanoparticles and temephos were used as negative and positive control, respectively. The larvicidal activity was estimated by the larvae mortality after $24 \mathrm{~h}, 48 \mathrm{~h}$ and $72 \mathrm{~h}$ of exposure. The toxicity of the encapsulated essential oil was also tested against $C$. lataniae Boisd. in a contact mode using a Potter spray tower. Prior to bioassays, ten adults were transferred at each plant. Unloaded nanoparticles and thymol (3.0 $\left.\mu \mathrm{g} \cdot \mathrm{mL}^{-1}\right)$ were used as negative and positive control, respectively. The spray volume was $3.0 \mathrm{~mL}$. Thereafter, the plants were kept individually at $25 \pm 1{ }^{\circ} \mathrm{C}, 90 \pm 5 \% \mathrm{RH}$. After $24 \mathrm{~h}, 48 \mathrm{~h}$ and $72 \mathrm{~h}$ of application, the number of live aphids was counted in each plant. Bioassays were performed in triplicate.

\section{Results and discussion}

\subsection{Essential oil characterization}

The essential oil condensation began around $0.5 \mathrm{~h}$ after the start of hydrodistillation, and the extraction time did not influence the essential oil yield. After $0.5 \mathrm{~h}$, no considerable concentration of essential oil was extracted. The optimum extraction time was $0.5 \mathrm{~h}$. The essential oil yield was found around $1.2 \%(\mathrm{w} / \mathrm{w})$. The essential oil density was found around $0.9114 \mathrm{~g} \cdot \mathrm{mL}^{-1}$, while the estimated refraction index was $1.51( \pm 0.01)$.

The chemistry of garlic is particular and it has been shown to develop a self-protective mechanism against microorganisms and other pathogens. This mechanism is related to the sulphur compounds that give to garlic its characteristic smell [1]. Chemical composition of the A. sativum essential oils is shown in Table 1.

Table 1. Essential oil composition of Allium sativum bulbs

\begin{tabular}{lll}
\hline Compounds & $* \mathbf{A I}_{\text {cal }}$ & Percentage \\
\hline allyl methyl disulfide & 910 & 3.10 \\
dimethyl trisulfide & 961 & 0.49 \\
diallyl disulfide & 1073 & 23.21 \\
allyl methyl trisulfide & 1131 & 13.62 \\
diallyl trisulfide & 1295 & 51.76 \\
diallyl tetrasulfide & 1535 & 0.92 \\
\hline Total (\%) & & 93.10 \\
\hline
\end{tabular}

*AIcal: Arithmetic Index relative to $\mathrm{C}_{7}-\mathrm{C}_{30} n$-alkanes on the TR-5 column.

GC-MS analyses allowed the identification of 6 constituents, representing 93.10\% of the essential oil in natura. Quantitative differences were clear for three compounds of the essential oil composition: diallyl trisulfide (51.8\%), diallyl disulphide (23.2\%) and allyl methyl trisulfide (13.6\%). The most characteristic volatile and odorous organosulfur compounds of garlic are released after the disruption of the cell membrane, causing the $\alpha, \beta$-elimination of alliin and other sulfoxides, which are located at the cytoplasm level, by the enzyme alliinase at the vacuole [29]. Various factors that affect the chemical composition of garlic are involved in the production process and could be useful to enhance the quality and bioactive properties of the final product [2].

\subsection{Antioxidant and AChE inhibitory activities}

The antioxidant activity in $\mathrm{DPPH}^{\circ}$ and $\mathrm{ABTS}^{*+}$ assays reflects the hydrogen donating ability of a given compound. The A. sativum essential oil have shown no sequestration capacity of $\mathrm{DPPH}^{*}$ and $\mathrm{ABTS}^{-+}$in the tested concentrations. Moreover, the tested oil also did not presente AChE inhibitory activity in the tested concentrations. These results may be useful for the evaluation of the essential oil effect on the mortality of A. aegypti and C. lataniae. Several factors are involved in the production of certain metabolites by plants. Through the DPPH radical 
scavenging capacity assay the low antioxidant potential of $A$. sativum essential oil was directly related to the low concentration of secondary metabolites [30].

\subsection{Larvicidal and insecticidal bioassays using the essential oil in natura}

The results presented here show that the essential oil in natura of $A$. sativum can be an efficient alternative controlling agent of $A$. aegypti larvae. The $\mathrm{LD}_{50}$ and $\mathrm{LD}_{90}$ (Table 2) were found to be 30.7 and $46.4 \mu \mathrm{g} . \mathrm{mL}^{-1}$, respectively, after $24 \mathrm{~h}$ of exposure. After $48 \mathrm{~h}$ of exposure, the $\mathrm{LD}_{50}$ and $\mathrm{LD}_{90}$ were 25.3 and $42.0 \mu \mathrm{g} . \mathrm{mL}^{-1}$, respectively.

Table 2. $\mathrm{LD}_{50}$ and $\mathrm{LD}_{90}$ values of A. sativum essential oil against A. aegypti and C. lataniae.

\begin{tabular}{lllllll}
\hline & Time LC50 \pm SE & (LCL-UCL) & LC90 \pm SE & (LCL-UCL) & Regression Equation \\
\hline${ }^{a}$ A. aegypti & $24 \mathrm{~h}$ & $30.7 \pm 0.0$ & $26.4-33.7$ & $46.4 \pm 0.5$ & $41.0-60.1$ & $Y=(-10.64+0.05)+7.15 X$ \\
& $48 \mathrm{~h}$ & $25.3 \pm 0.0$ & $18.2-28.9$ & $42.0 \pm 0.5$ & $37.0-55.7$ & $Y=(-8.17+0.05)+5.82 X$ \\
& $72 \mathrm{~h}$ & $21.3 \pm 0.0$ & $16.3-24.3$ & $36.3 \pm 0.5$ & $33.5-40.9$ & $Y=(-7.32+0.05)+5.51 X$ \\
\hline${ }^{b}$ C. lataniae & $24 \mathrm{~h}$ & $65.4 \pm 0.5$ & $35.6-129.7$ & $176.5 \pm 0.5$ & $48.2-361.4$ & $Y=(-1.62+0.05)+0.89 X$ \\
& $48 \mathrm{~h}$ & $16.8 \pm 0.5$ & $5.9-27.3$ & $172.8 \pm 0.5$ & $101.1-588.4$ & $Y=(-1.53+0.05)+1.25 X$ \\
& $72 \mathrm{~h}$ & - & - & - & - & - \\
\hline
\end{tabular}

* $L D_{50}$ : Lethal Dosage that kills $50 \%$ of the exposed larvae, expressed in $\mu$ g.mL $\mathrm{mL}^{-1} ; L D_{90}$ : Lethal Dosage that kills $90 \%$ of the exposed larvae, expressed in $\mu$ g.mL ${ }^{-1} ; Y$ : mortality rate (significant at $P<0.05$ level); $X$ : concentration (significant at $P<0.05$ level); SD: Standard Deviation; $L C L$ : Lower Confidence Limit; UCL: Upper Confidence Limit. ${ }^{a}$ Negative control: DMSO;

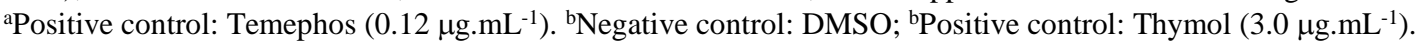

Total mortality was obtained after $72 \mathrm{~h}$ of exposure, reaching the concentrations of 21.3 and $36.3 \mu \mathrm{g} . \mathrm{mL}^{-1}$, respectively, for $\mathrm{LD}_{50}$ and $\mathrm{LD}_{90}$. Based on our previous results (section 3.2) showing no antioxidant nor AChE inhibitory activities, it is unknown whether the activity of the essential oil is due to the individual compounds or to synergistic interactions between their constituents. The electrophysiologically and behaviourally responds from Aedes aegypti to constituents of the essential oil of garlic were reported previously [31], and revealed that diallyl trisulfide and diallyl tetrasulfide applied to human showed protection against female mosquitoes significantly longer than the control.

The essential oil activity against insect pests can occur in different ways, causing mortality, deformations in different stages of development, as well as repellency. However, the essential oil dosage needed to control insect pests and their action mechanisms are potentially important for the safety of humans and other vertebrates [3,32]. The essential oils have shown insect toxicity in vapour phase, being reported as more toxic to the microorganisms than the contact phase [25]. Table 2 also shows the Lethal Dosages (LD) for $50 \%\left(\mathrm{LD}_{50}\right)$ and $90 \%$ (LD90) of mortality. For $C$. lataniae, the $\mathrm{LD}$ values were obtained as follow: $\mathrm{LD}_{50}=65.4 \mu \mathrm{g} \cdot \mathrm{mL}^{-1}$ and $\mathrm{LD}_{90}=176.5 \mu \mathrm{g} \cdot \mathrm{mL}^{-}$ ${ }^{1}$ for $24 \mathrm{~h}$; and $\mathrm{LD}_{50}=16.9 \mu \mathrm{g} \cdot \mathrm{mL}^{-1}$ and $\mathrm{LD}_{90}=172.8 \mu \mathrm{g} \cdot \mathrm{mL}^{-1}$ for $48 \mathrm{~h}$ of exposure, with $95 \%$ of fiducial limits. These results have shown high susceptibility of $C$. lataniae aphids to the chemical constituents of this essential oil.

\subsection{AFM analysis}

The nanoparticle size was estimated using the AFM technique and revealed that both types of nanoparticles (unloaded and loaded with essential oil) have spherical morphology and are well dispersed, as shown in Fig. 1a. The external surface of each nanoparticle is almost regular and smooth, showing that the PCL/gelatin forms a continuous film surrounding the essential oil droplets. The average size of the unloaded nanoparticles was found to be $290( \pm 5) \mathrm{nm}$.

The nanoparticles containing the $A$. sativum essential oil at concentration of $350 \mu \mathrm{g} \cdot \mathrm{mL}^{-1}$ also presented spherical morphology (Fig. 1b). The distribution size of the nanoparticles showed to be dependent on the essential oil concentration: the average size of $200( \pm 6) \mathrm{nm}$ was observed for the loaded nanoparticles. However, the size distribution is homogeneous for both systems. Polydispersity index were found 0.30 and 0.37 for unloaded and loaded nanoparticles, respectively.

\subsection{Zeta Potential and encapsulation efficiency}

Two different types of gelatin can be produced depending on the method in which collagen is pretreated, prior to the extraction process [11]. The isoelectric point of gelatin can be modified during its extraction from collagen to yield either a negatively charged acidic gelatin, or a positively charged basic gelatin [33]. In our case, the basic gelatin presented an isoelectric point of 5.0.

Zeta potential represents an important parameter for evaluation of charge, besides is related to the nanoparticle stability, influencing their size distribution. Simultaneous analysis of DLS and zeta potential as a function of $\mathrm{pH}$ were applied to the unloaded nanoparticles (data not shown) showed that they presented, in module, higher surface charge $(-10 \mathrm{mV})$ at basic $\mathrm{pHs}$ and seems to present stable charge between $\mathrm{pH}=5$ and $\mathrm{pH}=9$. 
(a)
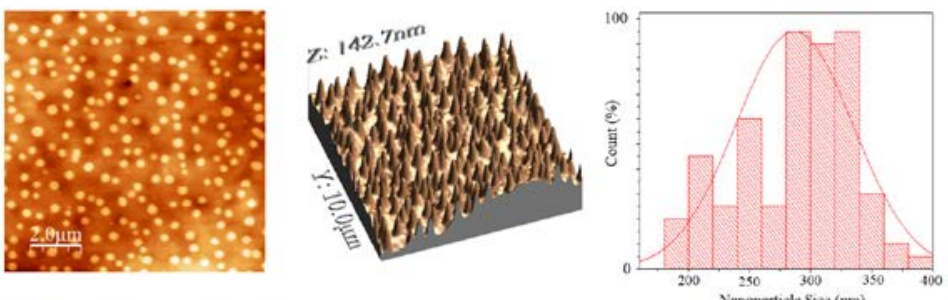

(b)
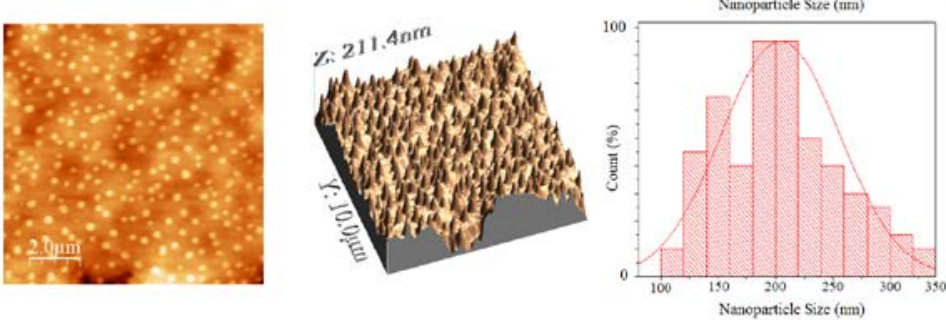

Fig. 1. Topography AFM images showing the nanoparticles spherical shape for (a) unloaded PCL/gelatin nanoparticles and (b) nanoparticles loaded with $350 \mu \mathrm{g} \cdot \mathrm{mL}^{-1}$ of A. sativum essential oil.

According to the zeta potential analysis the nanoparticles loaded with essential oil of the A. sativum presented values around $(-36 \pm 3) \mathrm{mV}$ for the concentration of $350 \mu \mathrm{g} \cdot \mathrm{mL}^{-1}$. The higher surface charge (in module) of the loaded nanoparticles can be attributed to the presence of the essential oil, contributing to their stabilization. It is known that the surface electrostatic charge of nanoparticles can be influenced by several factors, including surface functional groups and solution ions [34]. Gelatin has hydrophilic and hydrophobic amino acid groups in its structure, which are dependent on its type (A or B). The groups that give it a more pronounced hydrophobic behavior are present in type B (used in this work). A possible interaction between the essential oil with the hydrophilic group from gelation may be proposed, resulting in an exposing of the hydrophobic groups and assigning a negative charge to the system. The final surface charge of the encapsulated nanoparticles continues at a range that ensures their stability.

The encapsulation efficiency of the essential oil of A. sativum at absolute concentration of $350 \mu \mathrm{g} . \mathrm{mL}^{-1}$ was verified about $94.3 \%$.

\subsection{Controlled release of essential oil}

The release kinetics of the essential oil of A. sativum from PCL/gelatin-based nanoparticles were analyzed from cumulative release concentration versus time by fitting the data following the equation $\left.\left[\left(\mathrm{M}_{t} / \mathrm{M}_{\infty}\right)=\mathrm{kt}^{\mathrm{n}}\right)\right][10]$. $\mathrm{M}_{t} / \mathrm{M}_{\infty}$ represents the fractional active release at time $t ; n$ is a diffusion parameter characterizing the release mechanism, and $k$ is a constant characteristic of the active-polymer system [10,35,36]. Using the least squares procedure, the $k$ and $n$ values were estimated, as show in Table 3. If $n=0.5$, the active diffuses and releases from the polymer matrix following the quasi-Fickian diffusion. For $n<0.5$, occurs an anomalous or non-Fickian type of diffusion. If $n=1$, a completely non-Fickian case II or zero-order release kinetics is operative. Intermediary values between 0.5 and 1.0 are attributed to the anomalous type of transport.

Table 3. Models and coefficients of controlled release formulations

\begin{tabular}{|c|c|c|}
\hline Model & Coeff. & 350 нg.mL ${ }^{-1}$ \\
\hline \multirow[t]{2}{*}{ Zero order } & $k$ & 0.89 \\
\hline & $\mathrm{R}^{2}$ & 0.57 \\
\hline \multirow[t]{2}{*}{ First order } & $k$ & 0.26 \\
\hline & $\mathrm{R}^{2}$ & 0.90 \\
\hline \multirow[t]{2}{*}{ Higuchi } & $k$ & 12.89 \\
\hline & $\mathrm{R}^{2}$ & 0.86 \\
\hline \multirow[t]{3}{*}{ Korsmeyer-Peppas } & $k$ & 50.55 \\
\hline & $n$ & 0.14 \\
\hline & $\mathrm{R}^{2}$ & 0.95 \\
\hline
\end{tabular}

Fig. 2 shows the general controlled release curve of the A. sativum essential oil as a function of time. About $50 \%$ of the encapsulated essential oil was released after $1 \mathrm{~h}$. After $50 \mathrm{~h}$, around $90 \%$ of the encapsulated essential 
oil concentration was released. This behavior is interesting from the technological point of view since the nanoparticles need to release as much oil as possible in a short period of time so that the released concentration reached the needed lethal dosage. The first stage of release $(\mathrm{t}<1 \mathrm{~h})$ was initially fast while in the second stage ( $\mathrm{t}$ $>1 \mathrm{~h}$ ) a slower controlled release was observed.

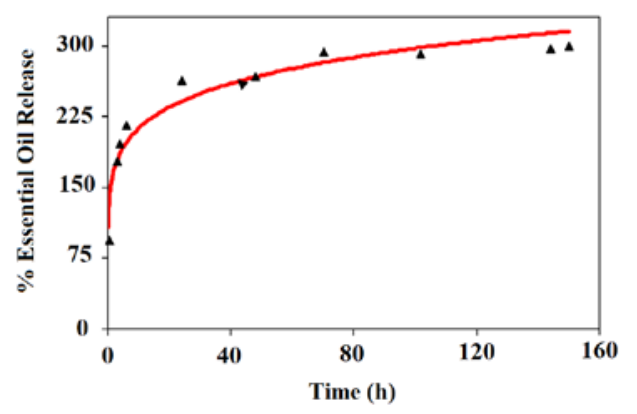

Fig. 2. Controlled release of the nanoparticles loaded with the A. sativum essential oil.

The high initial release rate can be explained by the rapid dissolution of the bioactive compound, which may be presented on the surface of the nanoparticles [37]. A high porosity and a high internal surface area of the nanoparticles may facilitate the solvent entry, increasing the dissolution and diffusion of the oil from nanoparticles [38]. Gelatin-based controlled release studies also observed a high release rate in the first few instants [37], favoring a high concentration of essential oil in the solvent, keeping it effective for a longer period of time [39].

As shown in Table 3, the Korsmeyer-Peppa model [40] better adjusted the controlled release data, with a higher average value of $\mathrm{R}^{2}$. For the controlled release kinetics of the encapsulated essential oil $n<0.43$, confirming the release mechanism by the Fick's Law. The coefficient $n$ is related to the type of release mechanism of compounds encapsulated in polymer matrices. Considering a spherical system, $n<0.43$ represents a mass transfer mechanism according to the Fick's Law, so the essential oil molecules diffuses according to a chemical potential gradient. For $0.43<n<0.83$, the release mechanism occurs according to an anomalous model in which the release is contributed by both the diffusion process and the relaxation of the polymer chains. The Case II occurs when $n$ is equal to 0.83 , indicating that the release of the substance is controlled by swelling of the system. For $\mathrm{n}>0.85$ the transport is known as a super case II in which there is a release acceleration due to erosion or mobility of the polymer chains $[7,41]$.

For the developed encapsulated system, the release of $100 \%$ of essential oil was not observed and may be explained by the strong interaction between the essential oil and the wall materials. Our results $(n=0.14)$ confirm a mass transfer mechanism according to the Fick's Law. Since the developed system is bilayer (one layer of PCL and another layer of gelatin), it is possible to suggest that the faster release observed in the first instants is due to the diffusion of the essential oil through the porous wall material formed by gelatin. In contrast, the slower observed diffusion mechanism also may be associated with the hydrophobic characteristics of the PCL layer, since this polymer is hardly degradable in water [42], and then the release of the essential oil becomes slower. In the study of diclofenac release in gelatin matrices [43], the Fickian compound release behavior was also observed.

\subsection{Bioassays using the loaded nanoparticles}

Nanoparticles containing the absolute concentrations of $350 \mu \mathrm{g} \cdot \mathrm{mL}^{-1}$ and $500 \mu \mathrm{g} \cdot \mathrm{mL}^{-1}$ of the encapsulated essential oil was submitted to in vitro bioassays against $A$. aegypti and $C$. lataniae. The results are shown in Table 4.

Table 4. Bioassays using the loaded nanoparticles against $A$. aegypti and C. lataniae

\begin{tabular}{|c|c|c|c|}
\hline A. sativum & Absolut Concentration ( $\mu$ g.mL $\mathrm{mL}^{-1}$ ) & Sample Number (N) & $\%$ Mortality after $24 \mathrm{~h}$ \\
\hline \multirow[t]{3}{*}{ A. aegypti } & 350 & 30 & 100 \\
\hline & 500 & 30 & 100 \\
\hline & Unloaded NPs & 30 & 0 \\
\hline \multirow[t]{3}{*}{ C. lataniae } & 350 & 30 & 100 \\
\hline & 500 & 30 & 100 \\
\hline & Unloaded NPs & 30 & 0 \\
\hline
\end{tabular}

* Larvae positive control: Thymol (3.0 $\mu$ g. $\left.\mathrm{mL}^{-1}\right)$; Aphids positive control: DMSO; Negative control: Unloaded PCL/gelatinbased nanoparticles. 
Nanoparticles containing essential oil showed $100 \%$ of mortality against larvae and aphids up to 24 h. These results show that the nanoparticles containing encapsulated essential oil of the specie $A$. sativum are efficient against the tested pests, causing their total mortality in short time due to the efficient controlled release of the lethal dosages.

\section{Conclusion}

The essential oil employed in this work represents an efficient alternative as controlling agent to combat $A$. aegypti larvae and $C$. lataniae aphids. The use of the essential oil from A. sativum was effective in a short time by killing them faster, reducing their reproduction potential. As this essential oil presented no potential antioxidant nor enzymatic activities, its effectiveness might be explained by the presence of sulfur compounds. The employment of this essential oil for the development of an encapsulated defensive is also safer for the environment and human health due to the low toxicity of the system as well as its short degradation time. In this point of view, this work has showed that this essential oil may represent an import candidate as an alternative natural defensive for a number of reasons: the abundance of this species around the world, and the ease of development of the nanoparticles used as wall material to encapsulate it. In conclusion, the essential oil from A. sativum may have potential to be used in sustainable management of pests in greenhouses, as well as for larvicidal control. However, further studies need to be conducted to evaluate the cost and large production of the developed system.

\section{Acknowlegments}

The authors thank Conselho Nacional de Desenvolvimento Científico e Tecnológico - CNPq (MCTI/CTAGRONEGÓCIO/CT-AMAZÔNIA, grant number 403496/2013-6) for the financial support.

\section{References}

[1] Lanzotti V, Scala F, Bonanomi G. Compounds from Allium species with cytotoxic and antimicrobial activity. Phytochemistry Reviews. 2014;13(4):769-791.

[2] Martins N, Petropoulos S, Ferreira IC. Chemical composition and bioactive compounds of garlic (Allium sativum L.) as affected by pre-and post-harvest conditions: A review. Food Chemistry. 2016;211:41-50.

[3] Isman MB. Botanical insecticides, deterrents, and repellents in modern agriculture and an increasingly regulated world. Annu. Rev. Entomol.. 2006;51:45-66.

[4] Souza LA, Lemos WP. Prospection of insects associated to açaí palm tree (Euterpe oleracea Mart.) in nursery and control propositions. Journal of Agricultural Sciences. 2004; 42: 231-241. (in Portuguese)

[5] Covarrubias C, Cádiz M, Maureira M, Celhay I, Cuadra F, von Marttens A. Bionanocomposite scaffolds based on chitosan-gelatin and nanodimensional bioactive glass particles: in vitro properties and in vivo bone regeneration. Journal of Biomaterials Applications. 2018;32(9):1155-1163.

[6] Campelo PH, Sanches EA, de Barros Fernandes RV, Botrel DA, Borges SV. Stability of lime essential oil microparticles produced with protein-carbohydrate blends. Food Research International. 2018;105:936-944.

[7] Felix PH, Birchal VS, Botrel DA, Marques GR, Borges SV. Physicochemical and thermal stability of microcapsules of cinnamon essential oil by spray drying. Journal of Food Processing and Preservation. 2017;41(3):e12919.

[8] Ghasemishahrestani Z, Mehta M, Darne P, Yadav A, Ranade S. Tunable synthesis of gelatin nanoparticles mploying sophorolipid and plant extract, a promising drug carrier. World J. Pharm. Pharm. Sci. 2015;4(7):1365-1381.

[9] Maji TK, Hussain MR. Microencapsulation of Zanthoxylum limonella oil (ZLO) in genipin crosslinked chitosan-gelatin complex for mosquito repellent application. Journal of Applied Polymer Science. 2009;111(2):779-785.

[10] Naidu BV, Paulson AT. A new method for the preparation of gelatin nanoparticles: Encapsulation and drug release characteristics. Journal of Applied Polymer Science. 2011;121(6):3495-3500.

[11] Young S, Wong M, Tabata Y, Mikos AG. Gelatin as a delivery vehicle for the controlled release of bioactive molecules. Journal of Controlled Release. 2005;109(1-3):256-274.

[12] Wu J, Liu H, Ge S, Wang S, Qin Z, Chen L, Zheng Q, Liu Q, Zhang Q. The preparation, characterization, antimicrobial stability and in vitro release evaluation of fish gelatin films incorporated with cinnamon essential oil nanoliposomes. Food Hydrocolloids. 2015;43:427-435.

[13] Hosseini SF, Zandi M, Rezaei M, Farahmandghavi F. Two-step method for encapsulation of oregano essential oil in chitosan nanoparticles: preparation, characterization and in vitro release study. Carbohydrate Polymers. 2013;95(1):50-56.

[14] Pfister G, Bahadir M, Korte F. Release characteristics of herbicides from Ca alginate gel formulations. Journal 
of controlled release. 1986;3(1-4):229-233.

[15] Perry RH, Green DW, Maloney JO. Densities of pure substances. 2008.

[16] Van den Dool H, Kratz PD. A generalization of the retention index system including linear temperature programmed gas-liquid partition chromatography. J. Chromatogr. A. 1963;11:463-471.

[17] McLafferty FW, Stauffer DB, Loh SY. Comparative evaluations of mass spectral data bases. Journal of the American Society for Mass Spectrometry. 1991;2(5):438-440.

[18] El-Sayed AM. The Pherobase: Database of pheromones and semiochemicals. The Pherobase;2014.

[19] Molyneux P. The use of the stable free radical diphenylpicrylhydrazyl (DPPH) for estimating antioxidant activity. Songklanakarin J. Sci. Technol. 2004;26(2):211-219.

[20] Re R, Pellegrini N, Proteggente A, Pannala A, Yang M, Rice-Evans C. Antioxidant activity applying an improved ABTS radical cation decolorization assay. Free Radical Biology and Medicine. 1999;26(910):1231-1237.

[21] Senol FS, Orhan IE, Ustun O. In vitro cholinesterase inhibitory and antioxidant effect of selected coniferous tree species. Asian Pacific Journal of Tropical Medicine. 2015;8(4):269-275.

[22] Dulmage HT, Correa JA, Gallegos-Morales G. Potential for improved formulations of Bacillus thuringiensis israelensis through standardization and fermentation development. In: Bacterial Control of Mosquitoes \& Black Flies. Dordrecht: Springer;1990. p. 110-133.

[23] Russell RM, Robertson JL, Savin NE. POLO: a new computer program for probit analysis. Bull. Entomol. Soc. Am. 1977;23(3):209-213.

[24] Aslan I, Özbek H, Çalmaşur Ö, Şahin F. Toxicity of essential oil vapours to two greenhouse pests, Tetranychus urticae Koch and Bemisia tabaci Genn. Industrial Crops and Products. 2004;19(2):167-173.

[25] Soylu EM, Soylu S, Kurt S. Antimicrobial activities of the essential oils of various plants against tomato late blight disease agent Phytophthora infestans. Mycopathologia. 2006;161(2):119-128.

[26] Gaddum JH. Probit analysis. 1948.

[27] Horcas I, Fernández R, Gomez-Rodriguez JM, Colchero JW, Gómez-Herrero JW, Baro AM. WSXM: a software for scanning probe microscopy and a tool for nanotechnology. Review of Scientific Instruments. 2007;78(1):013705.

[28] Schneider CA, Rasband WS, Eliceiri KW. NIH Image to ImageJ: 25 years of image analysis. Nature methods. 2012;9(7):671-675.

[29] Bloem E, Haneklaus S, Schnug E. Influence of fertilizer practices on S-containing metabolites in garlic (Allium sativum L.) under field conditions. Journal of Agricultural and Food Chemistry. 2010;58(19):1069010696.

[30] Fabri RL, Nogueira MS, Dutra LB, Bouzada MLM, Scio E. Antioxidant and antimicrobial potential of species from the Asteraceae Family. Brazilian Journal of Medical Plants. 2011; 13(2):183-189. (in Portuguese)

[31] Campbell C, Gries R, Khaskin G, Gries G. Organosulphur constituents in garlic oil elicit antennal and behavioural responses from the yellow fever mosquito. Journal of Applied Entomology. 2011;135(5):374381.

[32] Tripathi AK, Upadhyay S, Bhuiyan M, Bhattacharya PR. A review on prospects of essential oils as biopesticide in insect-pest management. Journal of Pharmacognosy and Phytotherapy. 2009;1(5):52-63.

[33] Tabata Y, Ikada Y. Protein release from gelatin matrices. Advanced drug delivery reviews. 1998;31(3):287301.

[34] Mahmoudi M, Lynch I, Ejtehadi MR, Monopoli MP, Bombelli FB, Laurent S. Protein- nanoparticle interactions: opportunities and challenges. Chemical Reviews. 2011;111(9):5610-5637.

[35] Sairam M, Babu VR, Naidu BV, Aminabhavi TM. Encapsulation efficiency and controlled release characteristics of crosslinked polyacrylamide particles. International Journal of Pharmaceutics. 2006;320(12):131-136.

[36] Ritger PL, Peppas NA. A simple equation for description of solute release II. Fickian and anomalous release from swellable devices. Journal of Controlled Release. 1987;5(1):37-42.

[37] Berardi A, Bisharat L, Cespi M, Basheti IA, Bonacucina G, Pavoni L, AlKhatib HS. Controlled release properties of zein powder filled into hard gelatin capsules. Powder Technology. 2017;320:703-713.

[38] Wischke C, Schwendeman SP. Principles of encapsulating hydrophobic drugs in PLA/PLGA microparticles. International Journal of Pharmaceutics. 2008;364(2):298-327.

[39] Peng H, Xiong H, Li J, Xie M, Liu Y, Bai C, Chen L. Vanillin cross-linked chitosan microspheres for controlled release of resveratrol. Food Chemistry. 2010;121(1):23-28.

[40] Lopes CM, Lobo JMS, Costa P. Pharmaceutical forms of modified release: hydrophilic polymers. Brazilian Journal of Pharmaceutical Sciences. 2006; 41:143-154. (in Portuguese)

[41] Korsmeyer RW, Peppas NA. Effect of the morphology of hydrophilic polymeric matrices on the diffusion and release of water soluble drugs. Journal of Membrane Science. 1981;9(3):211-227.

[42] Jeong JC, Lee J, Cho K. Effects of crystalline microstructure on drug release behavior of poly ( $\varepsilon$-caprolactone) 
microspheres. Journal of Controlled Release. 2003;92(3):249-258.

[43] Saravanan M, Bhaskar K, Maharajan G, Pillai KS. Development of gelatin microspheres loaded with diclofenac sodium for intra-articular administration. Journal of Drug Targeting. 2011;19(2):96-103.

(C) 2019 by the author(s). This work is licensed under a Creative Commons Attribution 4.0 International License (http://creativecommons.org/licenses/by/4.0/). Authors retain copyright of their work, with first publication rights granted to Tech Reviews Ltd. 